\title{
Severity of radiation pneumonitis, from clinical, dosimetric and biological features: a pilot study
}

Samantha Aso ${ }^{1,2}$, Arturo Navarro-Martin ${ }^{3^{*}} \mathbb{C}^{0}$, Richard Castillo ${ }^{4}$, Susana Padrones ${ }^{1}$, Edward Castillo ${ }^{4,5}$, Ana Montes ${ }^{2,9}$, José Ignacio Martínez ${ }^{1}$, Noelia Cubero ${ }^{1,9}$, Rosa López ${ }^{1,2}$, Laura Rodríguez ${ }^{6}$, Ramon Palmero ${ }^{7}$, Federico Manresa ${ }^{1,2,9}$, Thomas Guerrero ${ }^{4,5,8}$ and María Molina ${ }^{1,2,9^{*}}$

\begin{abstract}
Background and objective: Radiation pneumonitis (RP) could be a lethal complication of lung cancer treatment. No reliable predictors of RP severity have been recognized. This prospective pilot study was performed to identify early predictors of high grade lung toxicity and to evaluate clinical, biological or dosimetric features associated with different grades of toxicity.

Method: Sixteen patients with non-small cell lung cancer with indication of concurrent chemoradiotherapy using $60 \mathrm{~Gy} / 2 \mathrm{~Gy} /$ fraction starting at cycle one of platinum based chemotherapy were included. Bronchoalveolar lavage (BAL), pulmonary function testing (PFT), and ${ }^{18} \mathrm{~F}$-2-fluoro-2-deoxy-D-glucose positron-emission tomography was performed before radiotherapy (RT), after three weeks of treatment, and two months post-RT. For analysis, patients were grouped by grade (low [G1-G2] vs. high [G3-G5]). The two groups were compared to identify predictors of RP. Protein expression BAL and lung tissue metabolism was evaluated in two patients (RP-G1 vs. RP-G3). Categorical variables such as comorbidities, stages and locations were summarized as percentages. Radiation doses, pulmonary function values and time to RP were summarized by medians with ranges or as means with standard deviation. Longitudinal analysis PFT was performed by a T-test.
\end{abstract}

Results: All 16 patients developed RP, as follows: G1 (5 pts; 31.3\%); G2 (5 pts; 31.3\%); G3 (5 pts; 31.3\%); and G5 (1 pts; $6.1 \%)$. Patients with high grade RP presented significant decrease $(p=0.02)$ in diffusing lung capacity for carbon monoxide (DLCO) after three weeks of RT. No correlation between dosimetric values and RP grades was observed. BAL analysis of the selected patients showed that CXCL-1, CD154, IL-1 ra, IL-23, MIF, PAI-1 and IFN- $\gamma$ were overexpressed in the lungs of the RP-G3 patient, even before treatment. The pre-RT SUVmax value in the RP-G3 patient was nonsignificantly higher than in the patient with RP-G1.

Conclusions: RT induces some degree of RP. Our data suggest that decrease in DLCO\% is the most sensitive parameter for the early detection of RP. Moreover, we detect biological differences between the two grades of pneumonitis,

\footnotetext{
*Correspondence: anavarro@iconcologia.net; artnama79@gmail.com; mariamolinamolina@hotmail.com

${ }^{1}$ Department of Respiratory Medicine, Bellvitge University Hospital;

L'Hospitalet de Llobregat, Feixa Llarga S/N, 16th Floor, 08907 Barcelona,

Spain

${ }^{3}$ Department of Radiation Oncology, Catalan Institute of Oncology, L'Hospitalet de Llobregat, Feixa Llarga 199-203, 08908 Barcelona, Spain

Full list of author information is available at the end of the article
}

\section{$\triangle B M C$}

(c) The Author(s) 2020. This article is licensed under a Creative Commons Attribution 4.0 International License, which permits use, sharing, adaptation, distribution and reproduction in any medium or format, as long as you give appropriate credit to the original author(s) and the source, provide a link to the Creative Commons licence, and indicate if changes were made. The images or other third party material in this article are included in the article's Creative Commons licence, unless indicated otherwise in a credit line to the material. If material is not included in the article's Creative Commons licence and your intended use is not permitted by statutory regulation or exceeds the permitted use, you will need to obtain permission directly from the copyright holder. To view a copy of this licence, visit http://creativecommons.org/licenses/by/4.0/. The Creative Commons Public Domain Dedication waiver (http://creativecommons.org/publicdomain/zero/1.0/) applies to the data made available in this article, unless otherwise stated in a credit line to the data. 
highlighting the potential value of some cytokines as a prognostic marker for developing high grade lung toxicity. Further multicenter studies with larger sample size are essential to validate these findings.

Keywords: Non-small cell lung cancer, Radiation pneumonitis, Lung function, Wound healing

\section{Background}

Radiotherapy (RT) is a mainstay treatment for nonsmall cell lung cancer (NSCLC). Several studies have showed a benefit in local control and survival increasing biological equivalent doses [1]. However, its effectiveness is limited by the risk of radiation-induced lung injury (RILI). RILI is the result of an abnormal healing response to lung irradiation caused by damage to parenchymal cells, vasculature, and/or stroma followed by inflammatory cytokine release [2]. Diagnosis of RILI is based on nonspecific symptoms with or without abnormalities in pulmonary function tests (PFT). Radiographic changes usually reveal parenchymal abnormalities.

Radiation pneumonitis (RP), and pulmonary fibrosis (PF) represent, the acute and late phase of RILI. Symptomatic RILI has been described in $30 \%$ of cases, with mortality rates as high as 2\% [3-6]. Distinctions between these phases is arbitrary because early and late effects of RT are a continuous spectrum of the same biological event. Early-RILI or RP is considered when symptoms appear within 12 week after lung RT and up to 6 months post-RT. X-rays is characterized by inhomogeneous opacity inside or outside the irradiation field and increased density of septal structures. Late-RILI or PF is a chronic lung damage that usually evolves over 6 to 24 months after RT. X-rays shows contracted, dense scar that occupies a much smaller volume than the originally irradiated volume. Also fibroelastosis pleuroparenchymal changes can be observed do to RT [7].

The relationship between the development of RILI and baseline patient characteristics, lung function parameters and radiation dose have been retrospectively investigated $[3,8,9]$. Some molecular biomarkers in blood and bronchoalveolar lavage (BAL) have been proposed [10-12]. In addition, imaging technologies such as ${ }^{8} \mathrm{~F}$-2-fluoro-2-deoxy-D-glucose $\left({ }^{18} \mathrm{~F}-\mathrm{FDG}\right)$ positron-emission computed tomography (PET/CT) are able to quantify the uptake of ${ }^{18} \mathrm{~F}$-FDG in the lung as a marker of pulmonary inflammation [13-17]. Despite these advances, scarce data is available to show reliable predictive factors of RP, the effects of radiation on the lung, or the mechanisms leading to fibrosis and death in the context of RILI.

This prospective pilot study was conducted to identify early predictive factors of severity in RP and to evaluate the possible features associated with different grades of RP.

\section{Methods and material \\ Patients}

Patients diagnosed with NSCLC at our Institution with indication of concurrent chemoradiotherapy regimen using 60 Gy 2 Gy/fraction starting at cycle one of platinum based chemotherapy were prospectively included from January 2011 to March 2013. Inclusion criteria comprised: histologically confirmed NSCLC, inoperable locally advanced NSCLC, no previous thoracic RT. Exclusion criteria included: Karnofsky index $<70$, interstitial lung disease (ILD), forced expiratory volume at first second (FEV1) $<30 \%$, chronic respiratory failure, oral corticosteroid treatment, contraindication for bronchoscopy, or refusal to participate. The Ethics Committee of the University Hospital of Bellvitge and the Catalan Institute of Oncology approved the study protocol (PR206/08). Patients signed a written informed consent prior to inclusion.

Patients underwent BAL by fiberotpic-bronchoscopy, lung function testing, and ${ }^{18} \mathrm{FDG}-\mathrm{PET} / \mathrm{CT}$ prior to initiation of RT, at the end of the third week of RT, and at two months post-RT. Patient consultations were once weekly from the time of study inclusion until RT completion. Thereafter, patients were evaluated every 15 days for 6 months and then monthly for one year. The followup visits included: medical history, physical examination and monthly chest X-rays. RP diagnosis was based on the appearance or worsening of dyspnea and cough, which may associate fever or chest pain, accompanied with changes of radiological images. RP diagnosis and imaging evaluation were made by the multidisciplinary clinical team (medical oncologist, radiation oncologist and thoracic radiologist). RP grade was scored according to the Common Terminology Criteria for Adverse Events version 4.0. (CTCAEv4.0) [18]. Patients were divided into 2 groups (low-grade RP [G1 and G2], and high-grade RP [G3-G5]), according to the CTCAEv4.0. The two groups were compared to identify early predictors for high-grade RP development.

\section{Radiotherapy treatment}

Treatment planning for the RT used a 3D technique. An specific CT scan over the thorax and upper abdomen with intravenous contrast was obtained [19]. Gross tumor volume (GTV) was contoured according to the PET/CT and diagnostic CT scan. No prophylactic nodal irradiation was performed. To cover subclinical disease, 
the GTV was expanded according to histological findings. The GTV was increased by $0.6 \mathrm{~cm}$ for squamous cell carcinomas and by $0.8 \mathrm{~cm}$ for adenocarcinomas to provide the clinical target volume (CTV) [20]. The planning target volume (PTV) was determined by adding $0.7 \mathrm{~cm}$ to the CTV in the lateral and anterior posterior direction and $1.5 \mathrm{~cm}$ in the cranio-caudal direction [21]. The mean dose to the PTV was 60 Gy according to standard protocols [22]. Organs at risk were contoured in accordance with treatment guidelines [23]. Dose constrains to the lungs were $\mathrm{V} 20<35 \%$ (i.e., $35 \%$ of the healthy lung should receive $\leq 20 \mathrm{~Gy}$ ) with a mean dose $<19$ Gy. Radiotherapy and chemotherapy were started at the same time.

\section{Pulmonary function testing}

PFT parameters were measured according to European Respiratory Society guidelines [24] using computerized lung function testing equipment (Body Box 5500; Morgan Scientific). The parameters assessed included forced vital capacity (FVC), forced expiratory volume at first second (FEV1), and diffusing lung capacity for carbon monoxide (DLCO). The same technician performed the PFT at all follow-up consultations.

\section{BAL sample collection}

BAL was performed in both lungs (i.e., the irradiated and non-irradiated) by using four $40 \mathrm{~mL}$ aliquots of isotonic saline solution $(0.45 \%)$ per wash through a fiberopticbronchoscope (Olympus BF-160) to facilitate the extraction of cytokines and chemokines from the alveolar space. The first sample was discarded; the second and the third samples were mixed and sent for cytological evaluation. The fourth aliquot was centrifuged ( $543.6 \mathrm{~g} \times 5 \mathrm{~min}$ ) into cellular fraction and supernatant, which was aliquoted for cytokine determination; both fractions were frozen at $-80^{\circ} \mathrm{C}$.

\section{Protein array analysis of cytokine in BAL supernatant}

To evaluate differences in individual predisposition to lung damage and tissue repair response, we evaluate BAL samples. In this preliminary report, we chose one representative patient from each study group: one from low grade RP (RP-G1) and another from high grade RP (RPG3). Expression protein was assessed using the Human Cytokine Array Panel A (R\&D Systems, Minneapolis, MN; USA). Protein concentration was measured in each sample [25]. Pixel density of the spots was analysed using the Multi Gauge V3.0 (FujiFilm, Palo Alto, CA; USA). Three independent readers compared the mean pixel density values in the spots.

\section{Positron-emission computed tomography}

Patients underwent PET/CT imaging with ${ }^{18} \mathrm{~F}-\mathrm{FDG}$ according to standard practice [26]. They were asked to fast $6 \mathrm{~h}$ prior to the imaging session to ensure fasting blood glucose levels within the normal range (3.3-5.6 $\mathrm{mmol} / \mathrm{L})$. Patients received an intravenous administration of FDG per $\mathrm{kg}$ of body weight. The ${ }^{18}$ F-FDG-PET/CT scan was performed with a hybrid PET/CT scanner (General Electric Discovery ST). The whole-body acquisition protocol included a CT scan and a PET scan in a three-dimensional mode. No iodine intravenous contrast was administered. The CT data were used for attenuation correction and anatomic location of PET findings. The standardized uptake value (SUV) was used to measure uptake in the lungs.

\section{Image analysis}

Pre-treatment PET/CT image analyses of the two patients (i.e., RP-G1 and RP-G3) were performed to screen for possible differences in the SUV. This analysis was processed by three independent readers and evaluated using custom Matlab software (v2011a, Mathworks, Inc; Natick, MA; USA). The lung region of interest (ROI) was segmented semi-automatically. Overlap of central airway, liver, heart, diaphragm, and tumor in the lung ROI were manually removed. The resulting binary lung ROI was used for the analysis. The SUV was calculated from the PET attenuation corrected emission images [27]. SUV of voxels in the lung ROI were binned into histograms; the maximum SUV (SUVmax) was calculated according to the formula described by Petit el al. [15].

\section{Statistical analysis}

Since the prevalence of RP is variable due to differences in diagnostic scales [4], sample size was calculated using the "observed versus a reference mean" [28], which includes the reported prevalence of RP among the interstitial lung disease [29]. To detect a relevant clinical difference (alpha $=0.05$ and beta $=0.1), 17$ patients were required (assuming a follow-up loss rate of 20\%).

Patients were divided into 2 groups (low-grade [G1 and G2], and high-grade [G3-G5]), according to the CTCAEv4.0. The two groups were compared to identify predictors for the early identification of RILI. Categorical variables were summarized as percentages. Ordinal categorical variables were summarized by medians with ranges or as means with standard deviation (SD). Longitudinal analysis of FEV1(\%) and $\mathrm{DLCO}(\%)$ was performed by a $T$-test. Differences were considered statistically significant for $p<0.05$. All plots and analyses 
were performed using the statistical software $\mathrm{R}$ version 3.2.1 for Windows.

\section{Results}

Population

Seventeen patients were invited to participate and one refused. A total of 16 patients were included. Table 1 shows the characteristics of the cohort.All patients developed RP, with different grades of severity distributed as follows: 5 patients, G1 (31.3\%); 5 patients, G2 (31.3\%); 5 patients, G3 (31.3\%); and 1 patient, G5 (6.1\%) who died 3 weeks after beginning the treatment. The rest of them had one year of follow-up from the start of concurrent chemoradiotherapy. Patients were grouped by RP grade (low [G1-G2] vs. high [G3-G5]), with 10 and 6 patients in each group, respectively. Four patients from the highgrade group developed RILI in both lungs.

Table 2 shows the patient characteristics by RP group (low vs. high grade). There were no significance differences between the groups in terms of age, gender, comorbidities, PFT baseline values, cancer histology, stage and tumor localization. No differences were observed in the time of onset of RP and severity $(p=0,6642)$. The mean radiation dose was higher in the high-grade group [18 Gy (15.2 Gy-20.1 Gy) vs. 16.1 Gy (12 Gy-22.2 Gy)]; however, V20 was lower in the high-grade group [29.5 Gy (95\% CI $23-30)$ vs. 32 Gy (95\% CI 21-35)]. No significant correlation between dosimetric values and RP grades was observed.

\section{Pulmonary function testing}

Baseline FEV1(\%) and DLCO(\%) at diagnosis was not associated with the different grade of RP development. No significant differences in mean values were found between the groups at the three time points (baseline, end of week three, and at two month post-RT) (Tables 3 and 4). However, by the end of the third week of RT, the $\mathrm{DLCO}(\%)$ had decreased substantially in those cases that developed high-grade group ( $p=0.0203)$ (Fig. 1-B). Furthermore, the DLCO $(\%)$ decline was even worse after 2 months post-RT in that same group $(p=0.0342)$ (Fig. 1B). A FEV1(\%) decline was observed after 2 months of RT but not earlier during the treatment (Fig. 1-A). Therefore, the $\mathrm{DLCO}(\%)$ decrease during the RT allows to predict a high-grade RP even before starting respiratory symptoms.

\section{Protein array analysis in the BAL supernatant}

Different cytokine and chemokine expression profile (pre-RT and week 3) was found in a patient with RP-G1 compared to another with RP-G3 (Fig. 2). Before RT (Fig. 2-A), the only protein expressed in the tumorfree lung of the RP-G1 patient was ICAM while the

\begin{tabular}{|c|c|}
\hline Characteristics & \\
\hline No. of patients & 16 \\
\hline \multicolumn{2}{|l|}{ Sex } \\
\hline Male & $14(87.5 \%)$ \\
\hline Female & $2(12.5 \%)$ \\
\hline Age (range) & $63(58.8-76)$ \\
\hline \multicolumn{2}{|l|}{ Smoking history } \\
\hline Current & $10(62.5 \%)$ \\
\hline Former & $5(31.2 \%)$ \\
\hline Never & $1(6.2 \%)$ \\
\hline \multicolumn{2}{|l|}{ Pulmonary function (range) } \\
\hline FVC (\%) & $101(87-105.8)$ \\
\hline FEV1 (\%) & $85.5(71.5-93.3)$ \\
\hline FEV1/FVC & $67.9(60.5-73)$ \\
\hline DLCO (\%) & $71(57.2-87.5)$ \\
\hline \multicolumn{2}{|l|}{ Comorbidities } \\
\hline Hypertension & $5(31.2 \%)$ \\
\hline Diabetes & $3(18.8 \%)$ \\
\hline COPD & $11(68.8 \%)$ \\
\hline Heart disease & $2(12.5 \%)$ \\
\hline Vascular disease & $2(12.5 \%)$ \\
\hline \multicolumn{2}{|l|}{ Histologic type } \\
\hline Adenocarcinoma & $4(25 \%)$ \\
\hline Squamous cell carcinoma & $9(56.2 \%)$ \\
\hline Large cell neuroendocrine carcinoma & $2(12.5 \%)$ \\
\hline NSCLC & $1(6.2 \%)$ \\
\hline \multicolumn{2}{|l|}{ Location } \\
\hline Mediastinum & $1(6.2 \%)$ \\
\hline Hilar & $3(18.8 \%)$ \\
\hline Right upper lobe & $6(37.5 \%)$ \\
\hline Right inferior lobe & $2(12.5 \%)$ \\
\hline Left superior lobe & $3(18.8 \%)$ \\
\hline Left inferior lobe & $1(6.2 \%)$ \\
\hline \multicolumn{2}{|l|}{ Radiation doses (range) } \\
\hline Mean dose (Gy) & $17.2(12.7-22.9)$ \\
\hline V20 (\%) & $30(20.3-35.8)$ \\
\hline V5 (\%) & $60(47.5-65.8)$ \\
\hline \multicolumn{2}{|l|}{ Pneumonitis grades } \\
\hline 1 & $5(31.3 \%)$ \\
\hline 2 & $5(31.3 \%)$ \\
\hline 3 & $5(31.3 \%)$ \\
\hline 4 & $0(0 \%)$ \\
\hline 5 & $1(6.1 \%)$ \\
\hline
\end{tabular}


Table 2 Patient characteristics according to pneumonitis grade: low vs. high grade

\begin{tabular}{|c|c|c|}
\hline Characteristics & Low grade (G1-G2) & High grade (G3-G5) \\
\hline No. of patients & $10(62.5 \%)$ & $6(37.5 \%)$ \\
\hline \multicolumn{3}{|l|}{ Sex } \\
\hline Male & $9(90 \%)$ & $5(83.3 \%)$ \\
\hline Female & $1(10 \%)$ & $1(16.7 \%)$ \\
\hline Age (range) & $66.0(59.2-67)$ & $59.5(58.2-65.2)$ \\
\hline \multicolumn{3}{|l|}{ Smoking history } \\
\hline Current & $8(80 \%)$ & $2(33.3 \%)$ \\
\hline Former & $2(20 \%)$ & $3(50 \%)$ \\
\hline Never & $0(0 \%)$ & $1(16.7 \%)$ \\
\hline \multicolumn{3}{|l|}{ Pulmonary function (range) } \\
\hline FVC (\%) & $100,5(88.5-106.5)$ & 102.5(82.5-104.8) \\
\hline FEV1 (\%) & $81.5(59-93)$ & $89(77-90.5)$ \\
\hline FEV1/FVC & $64(55-71.6)$ & $69.5(67.9-80.3)$ \\
\hline DLCO (\%) & $71(46.8-83.5)$ & $71.5(63.5-92.2)$ \\
\hline \multicolumn{3}{|l|}{ Comorbidities } \\
\hline Hypertension & $3(30 \%)$ & $2(33.3 \%)$ \\
\hline Diabetes & $0(0 \%)$ & $3(50 \%)$ \\
\hline COPD & $7(70 \%)$ & $4(66.7 \%)$ \\
\hline Heart disease & $1(10 \%)$ & $1(16.7 \%)$ \\
\hline Vascular disease & $2(20 \%)$ & $0(0 \%)$ \\
\hline \multicolumn{3}{|l|}{ Histologic type } \\
\hline Adenocarcinoma & $3(30 \%)$ & $1(16.7 \%)$ \\
\hline Squamous cell carcinoma & $5(50 \%)$ & $4(66.7 \%)$ \\
\hline Large cell neuroendocrine carcinoma & $2(20 \%)$ & $0(0 \%)$ \\
\hline NSCLC & $0(0 \%)$ & $1(16.7 \%)$ \\
\hline \multicolumn{3}{|l|}{ Clinical stage } \\
\hline$\| \mathrm{B}$ & $3(30 \%)$ & - \\
\hline$\| \mathrm{A}$ & $6(60 \%)$ & $3(50 \%)$ \\
\hline IIIB & $1(10 \%)$ & $5(50 \%)$ \\
\hline \multicolumn{3}{|l|}{ Location } \\
\hline Mediastinum & $1(10 \%)$ & $0(0 \%)$ \\
\hline Hilar & $2(20 \%)$ & $1(16.7 \%)$ \\
\hline Right upper lobe & $4(40 \%)$ & $2(33.3 \%)$ \\
\hline Right inferior lobe & $1(10 \%)$ & $1(16.7 \%)$ \\
\hline Left superior lobe & $1(10 \%)$ & $2(33.3 \%)$ \\
\hline Left inferior lobe & $1(10 \%)$ & $0(0 \%)$ \\
\hline \multicolumn{3}{|l|}{ Chemotherapy agents } \\
\hline Carboplatin-etoposide & $1(10 \%)$ & $1(16.7 \%)$ \\
\hline Carboplatin-gemcitabina & $1(10 \%)$ & $0(0 \%)$ \\
\hline Cisplatin-vinorelbine & $2(20 \%)$ & $0(0 \%)$ \\
\hline Cisplatina-etoposide & $6(60 \%)$ & $5(83.3 \%)$ \\
\hline \multicolumn{3}{|l|}{ Radiation doses (range) } \\
\hline Mean dose(Gy) & $16.1(12-22.2)$ & $18(15.2-20.1)$ \\
\hline V20 (\%) & $32(21-35.8)$ & $29.5(23-30)$ \\
\hline Onset of radiation pneumonitis (median) & 68,5 days & 111 days \\
\hline
\end{tabular}

FVC: forced vital capacity, FEV1, forced expiratory volume in one second, DLCO: diffusing lung capacity for carbon monoxide, COPD: chronic obstructive pulmonary disease, NSCLC: non- small cell lung cancer 
Table 3 Mean values in FEV1 between CTCAEv4.0 groups at baseline, end of third week, and two month post-RT

\begin{tabular}{llll}
\hline Mean values & $\begin{array}{l}\text { Low grade (G1- } \\
\text { G2) }\end{array}$ & $\begin{array}{l}\text { High grade (G3- } \\
\text { G5) }\end{array}$ & $\boldsymbol{p}$ Value \\
\hline Baseline & $78.2 \%($ SD 21.2) & $88.5 \%($ SD: 19.1) & 0.2803 \\
3 weeks of RT & $93.4 \%$ (SD 17.5) & $86.2 \%($ SD: 22.4) & 0.0668 \\
2 months post-RT & $78.7 \%($ SD: 12.0) & $76.4 \%(S D$ 11.8) & 0.3015 \\
\hline
\end{tabular}

FEV1: forced expiratory volume in one second, CTCAEv4.0: common terminology criteria for Adverse Events version 4.0, RT: radiotherapy, SD: standard deviation

Table 4 Mean values in DLCO between CTCAEv4.0 groups at baseline, end of third week, and two month post-RT

\begin{tabular}{|c|c|c|c|}
\hline Mean values & $\begin{array}{l}\text { Low grade (G1- } \\
\text { G2) }\end{array}$ & $\begin{array}{l}\text { High grade (G3- } \\
\text { G5) }\end{array}$ & $p$ Value \\
\hline Baseline & $67.7 \%$ (SD 22.4) & $83.3 \%$ (SD: 30.2) & 0.0719 \\
\hline 3 weeks of RT & $62.8 \%$ (SD 11.5) & $65.6 \%$ (SD: 21.6) & 0.2136 \\
\hline 2 months post- RT & 57\% (SD: 13.6) & $55.2 \%$ (SD 16.7) & 0.0595 \\
\hline
\end{tabular}

DLCO: diffusing lung capacity for carbon monoxide, CTCAEv4.0: common terminology criteria for adverse events version 4.0, RT: radiotherapy, SD: standard deviation

tumor-free lung of the RP-G3 patient presented an overexpression of CD154, CXCL-1, ICAM, IFN- $\gamma$, IL-1ra, IL-23, MIF and PAI-1. In the lung with tumor (Fig. 2A), the RP-G1 patient expressed CXCL-1, ICAM, IL1ra and MIF while the RP-G3 patient showed those same cytokines but also expressed CD154, IL-23, IFN- $\gamma$ and PAI-1. At the end of third week of RT (Fig. 2-B), a change in the cytokine and chemokine patterns was detected in both cases. RT induced expression of CD154, CXCL-1, IL-1ra, IL-23, MIF, and PAI-1 while reducing ICAM expression in both lungs of the RP-G1 patient. RT increased cytokine response of the most overexpressed proteins in the tumor and tumor-free lungs of the RP-G3 patient, with a higher expression of CD154, CXCL1, IL1ra, IFN- $\gamma$, IL-23 and PAI-1 (Fig. 2-B).

\section{$\mathrm{PET} / \mathrm{CT}$ image analysis}

The pre-RT SUVmax value was calculated for the RP-G1 and RP-G3 patients. In both patients, the pre-treatment SUVmax was higher than normal (standardized lung SUVmax values, $0.05 \pm 0.17$ ) [30]. However, the RP-G3 patient had a non-significantly higher SUVmax (2.20 vs. 2 , respectively).

\section{Discussion}

The present study demonstrates that RT induces RILI in all patients who undergo external RT with variable clinical manifestations and different degrees of lung damage. This variability in the degree of RILI suggests that severe $\mathrm{RP}$ may be associated with differences in individual

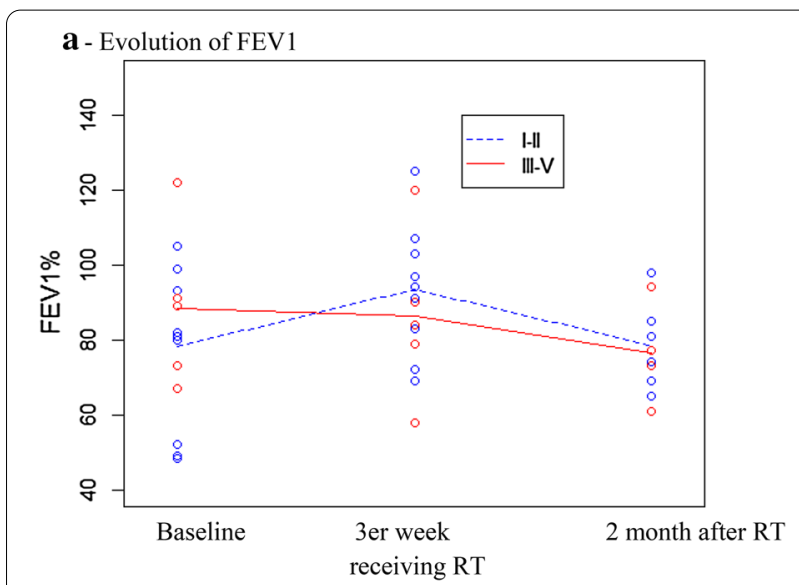

b- Evolution of DLCO values

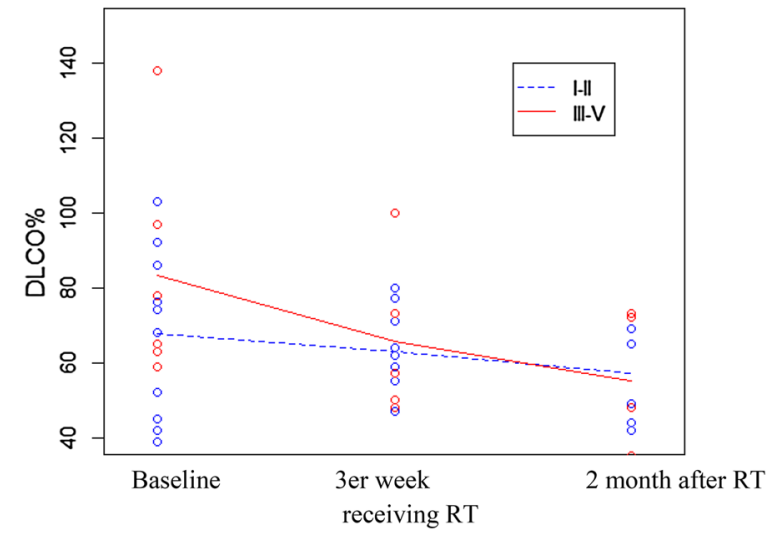

Fig. 1 Pulmonary function test values at different time-points by CTCAEv4.0 groups (low-grade [GI and GII] and high-grade [GIII-GV]). a Evolution of FEV1: The points represent the FEV1 (\%) value of each patient at the three different observation times. The straight, is the mean FEV1 (\%) value at each observation time. CTCAEv4.0: Common Terminology Criteria for Adverse Events version 4.0 FEV1: forced expiratory volume in one second RT: radiotherapy. $\mathbf{b}$ Evolution of DLCO values: The points represent the DLCO (\%) value of each patient at three different observation times. The straight line is the mean DLCO (\%) value at each observation time. CTCAEv4.0: Common Terminology Criteria for Adverse Events version 4.0 DLCO: diffusing lung capacity for carbon monoxide RT: radiotherapy

predisposition. The early decrease of $\mathrm{DLCO}(\%)$ was a predicting factor of severe RP development and thus could serve as a marker for early diagnosis and treatment modification.

The reported prevalence of RP in lung cancer patients ranges from 0 to $58 \%$ [4]. This variation is likely due to differences in diagnostic scales, non-specific symptoms, and the lack of standardized assessment protocols [4]. In the present study, standard follow-up protocols detected RILI in all of the patients but with different severity presentation. This finding suggests that all patients treated with RT are likely to develop RILI to a greater or lesser 


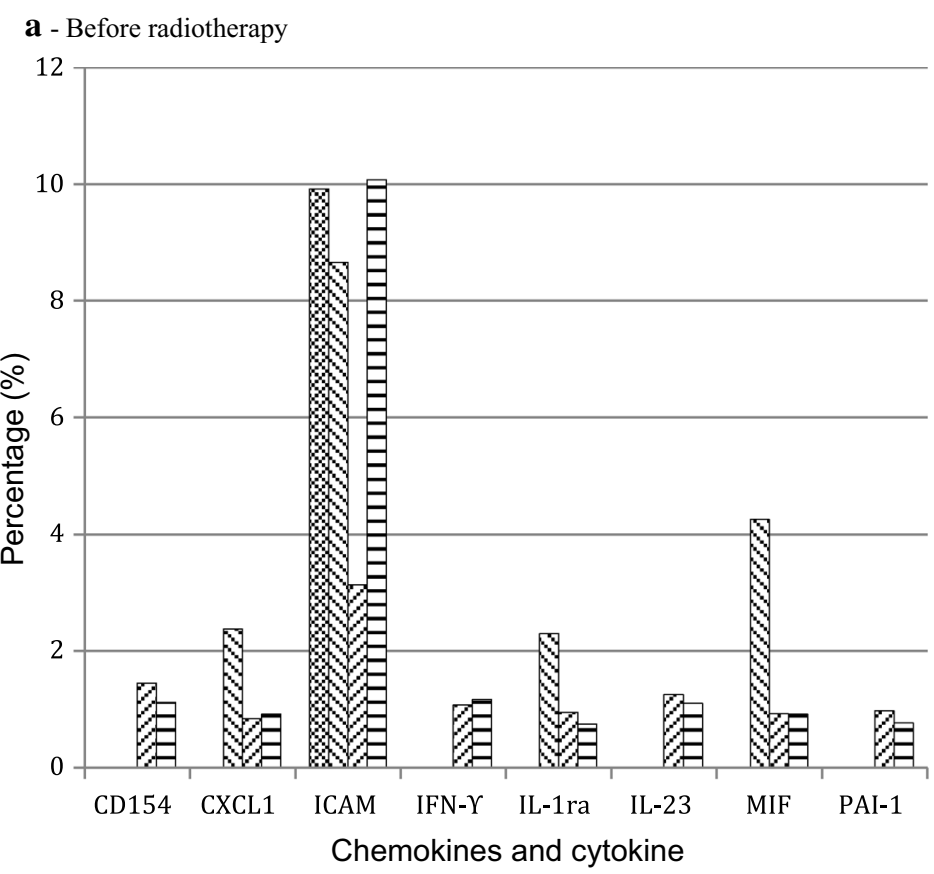

Q Pneumonitis grade 1 Lung without tumor

Q Pneumonitis grade 1 Lung with tumor

D Pneumonitis grade 3 Lung without tumor

目 Pneumonitis grade 3 Lung with tumor

b - Third week with radiotherapy

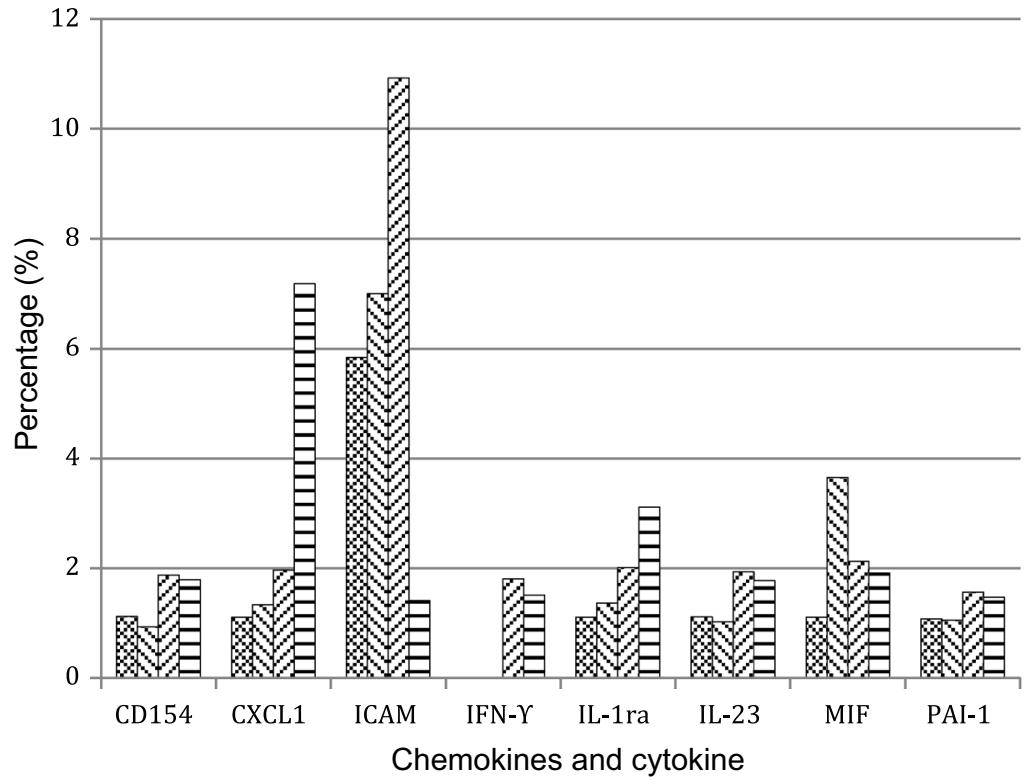

\% Pneumonitis grade 1 Lung without tumor

$\$$ Pneumonitis grade 1 Lung with tumor

¿. Pneumonitis grade 3 Lung without tumor

E Pneumonitis grade 3 Lung with tumor

Fig. 2 Cytokine and chemokines in bronchoalveolar lavage in patients with grade 1 and grade 3 radiation pneumonitis. a Before radiotherapy. $\mathbf{b}$ Third week with radiotherapy

extent, which may depend on individual biological characteristics.

Previous studies have shown that subtle, local changes in PFT after RT can be used as indicators of acute and chronic lung damage, although published results are not always consistent $[3,9]$. The largest and most consistent changes in PFT values after RT are observed in DLCO, which has been directly associated with respiratory morbidity [31]. In the present study, we evaluated the mean differences in FEV1(\%) and DLCO(\%) between low-grade RP patients [G1-G2] and high-grade RP patients [G3G5]. We found no statistically significant differences 
between the two groups in FEV1(\%) values at the different time points, thus leading us to conclude that FEV1(\%) is not a predictor of RP, a finding that is consistent with other reports $[9,31]$. By contrast, we found that a decrease in $\mathrm{DLCO}(\%) 2$ month post-RT was predictive of RP severity, in line with some previous reports $[9,31]$. Importantly, the decline in DLCO(\%) after three weeks of RT was an early predictor of severe RP. The explanatory power of this variable could be that histopathological alterations present during the latency phase (i.e., without clinical manifestations) for RILI may alter gas exchange [3]. Clearly, the ability to early predict severe RILI would be helpful to optimize therapeutic options.

Classically, RP grade has been associated with the radiation dose $[3,8]$. In our study, the high-grade group received a higher mean radiation dose but lower V20 than the low-grade group. This finding is contrast with the meta-analysis published by Palma et al. [32] The absence of a significant association in this study between $\mathrm{RP}$ grade and radiation parameters could be due to the limited sample size, the small differences among patients with regards to the radiation dose and biological predisposition [9].

The ${ }^{18}$ FDG-PET/CT has been use to quantify increase cell glycolysis in the healthy lung tissue, excluding tumoral areas, like a marker of pulmonary inflammation through the uptake of ${ }^{18} \mathrm{FDG}$ mesure by SUV [15-17]. It should be noted that both patients (RP-G1 and RP-G3) presented higher pre-RT SUVmax than normal values $(0.05 \pm 0.17)$ [30]. This finding could be explained by the role of chronic inflammation in lung cancer. Tumorgenesis includes a diverse leukocyte cells that has been considered key factors in tumor promotion since they release different variety of cytokines, chemokines, and cytotoxic. These mediators alter the adequate balance between proinflammatory and anti-inflammatory cytokines, favoring the increase of the first ones and producing a chronic inflammation state [33].

Accordingly, Castillo et al. [16, 17] demonstrated the predictive value of pre-treatment ${ }^{18} \mathrm{~F}$-FDG lung uptake in the subsequent development of RP symptoms. In this study, RP-G3 patient had a higher SUVmax in healthy lung tissue respect RP-G1 patient.These findings support the experience already published by Catillo et al.

RILI produce an imbalance between type 1 and type 2 helper T-cells and abnormal fibroproliferative wound healing [34]. Variations among patients in terms of RP severity and lung repair capacity could be related to individual pre-treatment lung biomolecular conditions and genetic factors [35]. In the present study, increased expression of some mediators were obtained in BAL of tumor lungs in both patients (RP-G1 and RP-G3), although these proteins were also expressed in the tumor-free lung of the RP-G3 patient before RT. Previous studies indicate that IL-1ra is involved in acute inflammation [36]; MIF modulates RILI [37]; and CXCL1 promotes angiogenesis and thus contribute to the pathogenesis of PF. [34] Interestingly, CD154, IFN- $\gamma$, IL-23 and PAI-1 were expressed in both lungs (tumor and tumorfree lung) before RT only in the RP-G3 patient. These four cytokines have been described in animal models of lung fibrosis [38, 39]. Furthermore, a recent study reported that a truncated PAI-1 protein protects against RILI in a murine model [40]. Finally, Liu et al. found that rs7242 GT/GG genotypes located in the 3ÚTR of PAI-1 were associated with a significantly increased risk of RP [41]. Overall, our findings suggest a potential biological predisposition to lung damage and altered wound healing in RILI development, which would deserve a depth study to better understand pathogenesis.

\section{Study strengths and limitations}

We have to recognize some limitations: First, the small sample size which was calculated using "observed versus a reference mean" and even although we have enrolled sixteen patients, instead of including seventeen, we have not had any loss of follow up. Secondly, the low power of the biological lung and the PET/CT image analysis (only two patients). In this sense, this is a pilot study to identify if there are differences in biological features associated with different grades of RP. Our findings, warrant further investigation in a larger sample. The main strength of the study is that it is the first prospective study to evaluate patients with NSCLC through a longitudinal clinical and biological follow-up that demonstrate RT induces RILI in all cases but in some of them with a high-grade of lung injury and consequent altered wound repair.

\section{Conclusion}

RT treatment always induces some degree of lung injury and the extent of the damage is variable. Our data suggest that decrease in DLCO\% is the most sensitive parameter for the early detection of severe RP. Moreover, we detect biological differences between the two grades of pneumonitis, highlighting the potential value of cytokines such as CXCL-1, CD154, IL-1ra, IL-23, MIF, PAI-1 and IFN- $\gamma$ as a prognostic marker for developing high grade of lung toxicity. Further multicenter studies with larger sample size are essential to validate these preliminary findings.

\section{Abbreviations}

CTCAEv4.0: Common terminology criteria for adverse events version 4.0; CXCL1: Chemokine (C-X-C motif) ligand 1; CTV: Clinical target volume; G1: Grade 1; G2: Grade 2; G3: Grade 3; G5: Grade 5; GTV: Gross tumour volume; ICAM: Intercellular adhesion molecular; IFN-Y: Interferon-gamma; IL-23: Interleukin-23; IL-1 ra: Interleukin-1 receptor antagonist; MIF: Macrophage migration 
inhibitory factor; PTV: Planning target volume; PAI-1: Plasminogen activator inhibitor type 1; RT: Radiotherapy; RP-G1: Radiation pneumonitis grade 1; RPG3: Radiation pneumonitis grade 3; ROI: Region of interest; TGF- $\beta 1$ : Transforming growth factor $\beta-1 ; \mathrm{V} 20$ : Healthy lung that should receive $\leq 20 \mathrm{~Gy}$.

\section{Acknowledgements}

Authors wish to thank Bradley Londres for editing the manuscript. Pilar Bayo and Gabriel Reynés (Department of Nuclear Medicine, Bellvitge Universitary Hospital and Physic Department, Catalan Institute of Oncology) for image analysis.

\section{Authors' contributions}

S.A., A.N and M.M. takes responsibility of the content and writing of manuscript. S.A., A.N., J.I.M., F.M, and M.M. designed the study. S.A., A.N, S.P., R.P, collected data. N.C and R.L performed the bronchoscopy S.A., L.R., R.C., E.C., and T.G., performed image analysis, S.A., A.M. and M.M., performed cytokine analysis A.N., R.C., S.P, E.C., A.M., J.I.M., N.C., R.L., L.R., R.P., F.M., J.D., and T.G., reviewed manuscript and approved final manuscript.

\section{Funding}

The Sociedad Española de Neumología y Cirugía Torácica (SEPAR) supported this project by a grant to finance the material expenses for the protein array analysis of cytokine, for statistical analysis and English corrector. The Insitut d'Investigació de Bellvitge (IDIBELL) supported this project by a grant to finance Samantha Aso PhD graduated student. These institutions haven't participated in the design or development of the study or in the writing of the document.

\section{Availability of data and materials}

The datasets are available to all interested researchers on reasonable request from corresponding author.

\section{Ethics approval and consent to participate}

The Ethics Committee of the University Hospital of Bellvitge and the Catalan Institute of Oncology approved the study protocol (PR206/08). Patients signed a written informed consent prior to inclusion.

\section{Consent for publication}

Not applicable.

\section{Competing interests}

M.M: she's consulting of Esteve-Teijin, Boehringer Ingelheim, Roche, Chiesi, GSK and Pfizer. Rest of authors: the authors declare that they have no competing interests.

\begin{abstract}
Author details
${ }^{1}$ Department of Respiratory Medicine, Bellvitge University Hospital: L'Hospitalet de Llobregat, Feixa Llarga S/N, 16th Floor, 08907 Barcelona, Spain. ${ }^{2}$ Laboratory of Respiratory Medicine, IDIBELL, Barcelona University; L'Hospitalet de Llobregat, Barcelona, Spain. ${ }^{3}$ Department of Radiation Oncology, Catalan Institute of Oncology, L'Hospitalet de Llobregat, Feixa Llarga 199-203, 08908 Barcelona, Spain. ${ }^{4}$ Divisions of Radiation Oncology, University of Texas MD Anderson Cancer Center, Houston, TX, USA. ${ }^{5}$ Department of Computational and Applied Mathematics, Rice University, Houston, TX, USA. ${ }^{6}$ Department of Nuclear Medicine, Bellvitge Universitary Hospital; L'Hospitalet de Llobregat, Barcelona, Spain. ${ }^{7}$ Department of Medical Oncology, Catalan Institute of Oncology: L'Hospitalet de Llobregat, Barcelona, Spain. ${ }^{8}$ The University of Texas Health Science Center, Houston, TX, USA. ${ }^{9}$ CIBER of Respiratory Diseases (CIBERES), ISCIII, Barcelona, Spain.
\end{abstract}

Received: 17 August 2020 Accepted: 21 October 2020

Published online: 27 October 2020

\section{References}

1. Ma L, Men Y, Feng L, Kang J, Sun X, Yuan M, Jiang W, Hui Z. A current review of dose-escalated radiotherapy in locally advanced non-small cell lung cancer. Radiol Oncol. 2019;53(1):6-14. https://doi.org/10.2478/ raon-2019-0006.
2. Rodemann HP. Molecular radiation biology: Perspectives for radiation oncology. Radiother Oncol. 2009;92:293-8. https://doi.org/10.1016/j. radonc.2009.08.023.

3. Madani I, De Ruyck K, Goeminne H, De Neve W, Thierens H, Van Meerbeeck J. Predicting risk of radiation-induced lung injury. J Thorac Oncol. 2007;2:864-74. https://doi.org/10.1097/JTO.0b013e318145b2c6.

4. Inoue A, Kunitoh H, Sekine I, Sumi M, Tokuuye K, Saijo N. Radiation pneumonitis in lung cancer patients: a retrospective study of risk factors and the long-term prognosis. Int J Radiat Oncol Biol Phys. 2001;49:649-55. https://doi.org/10.1016/s0360-3016(00)00783-5.

5. Kong FM, Ten Haken R, Eisbruch A, Lawrence TS. Non-small cell lung cancer therapy-related pulmonary toxicity: An update on radiation pneumonitis and fibrosis. Semin Oncol. 2005;32:S42-54. https://doi.org/10.1053/j. seminoncol.2005.03.009.

6. Wang JY, Chen KY, Wang JT, Chen JH, Lin JW, Wang HC, Lee LN, Yang PC. Outcome and prognostic factors for patients with non-small-cell lung cancer and severe radiation pneumonitis. Int J Radiat Oncol Biol Phys. 2002;54:735-41. https://doi.org/10.1016/s0360-3016(02)02994-2.

7. Portillo K, Arriaga I, Ruiz-Manzano J. Fibroelastosis pleuropulmonar: ¿es también una entidad idiopática? Arch Bronconeumol. 2015;51:509-14. https://doi.org/10.1016/j.arbres.2015.05.002.

8. Zhang XJ, Sun JG, Sun J, Ming H, Wang XX, Wu L, Chen ZT. Prediction of radiation pneumonitis in lung cancer patients: a systematic review. J Cancer Res Clin Oncol. 2012;138:2103-16. https://doi.org/10.1007/s0043 2-012-1284-1.

9. Kong F-MS, Wang S. Nondosimetric risk factors for radiation-induced lung toxicity. Semin Radiat Oncol. 2015; 25:100-9. DOI: https://doi. org/10.1016/j.semradonc.2014.12.003

10. Barthelemy-Brichant N, Bosquée L, Cataldo D, Corhay J-L, Gustin M, Seide L, Thiry A, Ghaye B, Nizet M, Albert A, Deneufbourg L-M, Bartsch P, Nusgens $B$. Increased IL-6 and TGF-beta1 concentrations in bronchoalveolar lavage fluid associated with thoracic radiotherapy. Int J Radiat Oncol Biol Phys. 2004;58:758-67. https://doi.org/10.1016/S0360-3016(03)01614-6.

11. Rübe CE, Palm J, Erren M, Fleckenstein J, König J, Remberger K, Rübe C. Cytokine plasma levels: reliable predictors for radiation pneumonitis? PLoS ONE. 2008;3:e2898. https://doi.org/10.1371/journal.pone.0002898.

12. Kong FM, Ao X, Wang L, Lawrence TS. The use of blood biomarkers to predict radiation lung toxicity: A potential strategy to individualize thoracic radiation therapy. Vol. 15, Cancer Control. 2008. p. 140-50. DOI: https:// doi.org/10.1177/107327480801500206

13. Guerrero T, Johnson V, Hart J, Pan T, Khan M, Luo D, Liao Z, Ajani J, Stevens C, Komaki R. Radiation pneumonitis: local dose versus [18F] fluorodeoxyglucose uptake response in irradiated lung. Int J Radiat Oncol Biol Phys. 2007;68:1030-5. https://doi.org/10.1016/j.jijobp.2007.01.031.

14. De RD, Houben A, Aerts HJWL, Dehing C, Wanders R, Öllers M, Dingemans A-MC, Hochstenbag M, Boersma L, Borger J, Dekker A, Lambin P. Increased 18F-deoxyglucose uptake in the lung during the first weeks of radiotherapy is correlated with subsequent Radiation-Induced Lung Toxicity (RILT): A prospective pilot study. Radiother Oncol. 2009;91:415-20. https://doi.org/10.1016/j.radonc.2009.01.004.

15. Petit SF, Van Elmpt WJC, Oberije CJG, Vegt E, Dingemans AMC, Lambin P, Dekker ALA, De Ruysscher D. [18F]fluorodeoxyglucose uptake patterns in lung before radiotherapy identify areas more susceptible to radiation-induced lung toxicity in non-small-cell lung cancer patients. Int J Radiat Oncol Biol Phys. 2011;81:698-705. https://doi.org/10.1016/j.jirob p.2010.06.016.

16. Castillo R, Pham N, Ansari S, Meshkov D, Castillo S, Li M, Olanrewaju A, Hobbs B, Castillo E, Guerrero TM. Pre-radiotherapy FDG PET predicts radiation pneumonitis in lung cancer. Radiat Oncol. 2014;9:74. https://doi. org/10.1186/1748-717X-9-74.

17. Castillo R, Pham N, Castillo E, Aso-Gonzales S, Ansari S, Hobbs B, Palacio D, Skinner H, Guerrero TM. Pre-radiation therapy fluorine helps identify patients with esophageal cancer at high risk for radiation pneumonitis. Radiology. 2015;275:822-31. https://doi.org/10.1148/radiol.14140457.

18. National Institute of Cancer. Common Terminology Criteria for Adverse Events (CTCAE ), Version 4.0, DCTD, CTI, NIH, DHHS. NIH Publication. 2009. 0-71 p. DOI: https://doi.org/10.1186/s12955-016-0426-6

19. De Ruysscher D, Faivre-Finn C, Nestle U, Hurkmans CW, Le Péchoux C, Price A, Senan S. European organisation for research and treatment of cancer recommendations for planning and delivery of high-dose, 
high-precision radiotherapy for lung cancer. J Clin Oncol. 2010;28:530110. https://doi.org/10.1200/JCO.2010.30.3271.

20. Giraud P, Antoine M, Larrouy A, Milleron B, Callard P, De Rycke Y, Carette MF, Rosenwald JC, Cosset JM, Housset M, Touboul E. Evaluation of microscopic tumor extension in non-small-cell lung cancer for threedimensional conformal radiotherapy planning. Int J Radiat Oncol Biol Phys. 2000;48:1015-24. https://doi.org/10.1016/s0360-3016(00)00750-1.

21. Senan S, Chapet O, Lagerwaard FJ, Ten HRK. Defining target volumes for non-small cell lung carcinoma. Semin Radiat Oncol. 2004;14:308-14. https://doi.org/10.1016/j.semradonc.2004.07.004.

22. Ramnath N, Dilling TJ, Harris LJ, Kim AW, Michaud GC, Balekian AA Diekemper R, Detterbeck FC, Arenberg DA. Treatment of stage III nonsmall cell lung cancer: diagnosis and management of lung cancer, 3rd ed: American college of chest physicians evidence-based clinical practice guidelines. Chest. 2013;143:e314S-340S. https://doi.org/10.1378/chest $.12-2360$.

23. Kong FM, Ritter T, Quint DJ, Senan S, Gaspar LE, Komaki RU, Hurkmans CW, Timmerman R, Bezjak A, Bradley JD, Movsas B, Marsh L, Okunieff P, Choy H, Curran WJ Jr, et al. Consideration of dose limits for organs at risk of thoracic radiotherapy: Atlas for lung, proximal bronchial tree, esophagus, spinal cord, ribs, and brachial plexus. Int J Radiat Oncol Biol Phys. 2011;81:1442-57. https://doi.org/10.1016/j.jijobp.2010.07.1977.

24. Brusasco V, Crapo R, Viegi G. Coming together: The ATS/ERS consensus on clinical pulmonary function testing. Eur Respir J. 2005;26:1-2. https://doi. org/10.1183/09031936.05.00034205

25. Lowry OH, Rosebrough FAL, Randall RJ. Protein measurement with the Folin phenol reagent. J Biol Chem. 1951;193:265-75.

26. Boellaard R, Doherty MJO, Weber WA, Mottaghy FM, Lonsdale MN, Stroobants SG, Oyen WJ, Kotzerke J, Hoekstra OS, Pruim J, Marsden PK, Tatsch K, Hoekstra CJ, Visser EP, Arends B, Verzijlbergen FJ, Zijlstra JM, Comans EF, Lammertsma AA, Paans AM, Willemsen AT, Beyer T, Bockisch A, SchaeferProkpo C, Delbeke D, Baum RP, Chiti A and Krause BJ. FDG PET and PET/ CT: EANM procedure guidelines for tumour PET imaging: version 1.0. Eur J Nucl Med Mol Imaging. 2010; 37:181-200. DOI: https://doi.org/10.1007/ s00259-009-1297-4

27. Strauss LG, Conti PS. The applications of PET in clinical oncology. J Nucl Med. 1991;32:623-48.

28. Marrugat J, Vila J, Pavesi M, Sanz F. Estimation of the sample size in clinical and epidemiological investigations. Med Clin (Barc). 1988;111(7):267-76.

29. Xaubet A, Ancochea J, Morell F, Rodríguez-Arias JM, Villena V, Blanquer R, Montero C, Sueiro A, Disdier C, Vendrell M, Spanish Group on Interstitial Lung Disease, SEPAR. Report on the Incidence of Interstitial Lung Diseases in Spain. Sarcoidosis Vasc Diffuse Lung Dis. 2004;21(1):64-70.

30. Ley JA, Borbón GA, Ochoa Carrillo FJ, Escobar RV, Rojas SH, Estrada G. Valor estandarizado de captación máximo, determinado con Tomografía Computarizada."Primera experiencia en México" (Spanish). An Radiol Mex. 2007; 6:113-9.

31. Lopez Guerra JL, Gomez DR, Zhuang Y, Levy LB, Eapen G, Liu H, Mohan R, Komaki R, Cox JD, Liao Z. Changes in pulmonary function after threedimensional conformal radiotherapy, intensity-modulated radiotherapy, or proton beam therapy for non-small-cell lung cancer. Int J Radiat Onco Biol Phys. 2012;83:E537-43. https://doi.org/10.1016/j.jijobp.2012.01.019.
32. Palma DA, Senan S, Tsujino K, Barriger RB, Rengan R, Moreno M, Bradley JD, Kim TH, Ramella S, Marks LB, De Petris L, Stitt L, Rodrigues G. Predicting radiation pneumonitis after chemoradiation therapy for lung cancer: an international individual patient data meta-analysis. Int J Radiat Oncol Biol Phys. 2013;85(2):444-50. https://doi.org/10.1016/j.jirobp.2012.04.043.

33. Gomes M, Teixeira AL, Coelho A, Araújo A and Medeiros R. the role of inflammation in lung cancer. In: B. B. Aggarwal et al. (eds.), Inflammation and cancer, advances in experimental medicine and biology. Porto: Springer Basel; 2014. p. 1-23. DOl: https://doi. org/10.1007/978-3-0348-0837-8_1

34. Keane MP. The role of chemokines and cytokines in lung fibrosis. Vol. 17, European Respiratory Review. 2008. p. 151-6.

35. Tang $W$, Yang L, Qin W, Yi MX, Liu B, Yuan XL. Impact of genetic variant of HIPK2 on the risk of severe radiation pneumonitis in lung cancer patients treated with radiation therapy. Radiat Oncol. 2020;15(1):9. https://doi. org/10.1186/s13014-019-1456-0.

36. Gasse P, Mary C, Guenon I, Noulin N, Charron S, Schnyder-Candrian S, Scsnyder B, Akira S, Quesniaux V.F.J, Lagente V, Ryffel B and Couillin I. IL-1R1/ MyD88 signaling and the inflammasome are essential in pulmonary inflammation and fibrosis in mice. J Clin Invest. 2007; 117:3786-99. DOl: https://doi.org/10.1172/JCl32285

37. Mathew B, Jacobson JR, Siegler JH, Moitra J, Blasco M, Xie L, Unzueta C, Zhou T, Evenoski C, Al-Sakka M, Sharma R, Huey B, Bulent A, Smith B, Jayaraman S, Reddy NM, Reddy SP, Fingerle-Rowson G, Bucala R, Dudek SM, Natarajan V, Weichselbaum RR and Garcia J.G.N. Role of migratory inhibition factor in age-related susceptibility to radiation lung injury via NF-E2-related factor-2 and antioxidant regulation. Am J Respir Cell Mol Biol. 2013; 49:269-78. DOl: https://doi.org/10.1165/rcmb.2012-02910C

38. Gasse P, Riteau N, Vacher R, Michel ML, Fautrel A, di Padova F, Fick L, Charron S, Lagente V, Eberl G, Le Bert M, Quesniaux VF, Huaux F, Leitede-Moraes M, Ryffel B, Couillin I. IL-1 and IL-23 mediate early IL-17A production in pulmonary inflammation leading to late fibrosis. PLoS ONE. 2011;6:e23185. https://doi.org/10.1371/journal.pone.0023185.

39. Kaufman J, Sime PJ, Phipps RP. Expression of CD154 (CD40 ligand) by human lung fibroblasts: differential regulation by IFN-gamma and IL-13, and implications for fibrosis. J Immunol. 2004;172:1862-71. https://doi. org/10.4049/jimmunol.172.3.1862.

40. Senoo T, Hattori N, Tanimoto T, Furonaka M, Ishikawa N, Fujitaka K, Haruta Y, Murai H, Yokoyama A, Kohno N. Suppression of plasminogen activator inhibitor-1 by RNA interference attenuates pulmonary fibrosis. Thorax. 2010;65:334-40. https://doi.org/10.1136/thx.2009.119974.

41. Liu B, Tang Y, Yi M, Liu Q, Xiong H, Hu G, Yuan X. Genetic variants in the plasminogen activator inhibitor-1 gene are associated with an increased risk of radiation pneumonitis in lung cancer patients. Cancer Med. 2017;6:681-8. https://doi.org/10.1002/cam4.1011.

\section{Publisher's Note}

Springer Nature remains neutral with regard to jurisdictional claims in published maps and institutional affiliations.
Ready to submit your research? Choose BMC and benefit from:

- fast, convenient online submission

- thorough peer review by experienced researchers in your field

- rapid publication on acceptance

- support for research data, including large and complex data types

- gold Open Access which fosters wider collaboration and increased citations

- maximum visibility for your research: over $100 \mathrm{M}$ website views per year

At BMC, research is always in progress.

Learn more biomedcentral.com/submissions 